\title{
Para uma contra-história do espetáculo moderno: primeiras notas sobre o teatro dos ciarlatani (charlatães)
}

For an anti-history of the modern show: first notes about the ciarlatani theater

Roberto Tessari ${ }^{1}$

Tradução: Ivanildo Lubarino Piccoli Santos ${ }^{2}$

\section{RESUMO}

Com base nos limitados documentos restantes, registrou-se um verdadeiro e próprio mercado moderno do espetáculo com os novos cerretani-ciarlatani, charlatães da praça, que assumiram o papel de terapeutas populares através de diversos recursos cênicos como as máscaras dos zanni. Estes ciarlatani-espetáculos constituíam uma estrutura para propiciar e explorar as expectativas do divertimento de um público não mais elitista, com um fim cômico - espetáculos de máscaras, os ciarlatani tornam-se comediantes e se servem da comédia como meio eficaz para atrair a venda de suas mercadorias e deixam um imenso legado na história dos espetáculos de lugares públicos.

Palavras-chave: Espetáculo moderno. Teatro dos ciarlatani.

História do teatro.

\section{ABSTRACT}

Sulla base dei limitati documenti rimasti, c’è stata un vero e proprio mercato moderno dello spettacolo, con nuovi cerretani-ciarlatani, ciarlatani di piazza, che ha assunto il ruolo di terapeuti popolare attraverso varie risorse teatrale come le maschere di Zanni. Questi ciarlatani-spettacoli erano una struttura per fornire ed esplorare le aspettative di divertimento di un pubblico non più elitaria, con un finale comico - spettacoli anche di maschere, $i$ ciarlatani diventano comici e servire la commedia come un mezzo efficace per attirare le vendite dei loro prodotti e lasciare un'eredità enorme nella storia dei luoghi pubblici spettacoli.

Keywords: Spettacolo moderno. Teatro dei ciarlatani. Storia del teatro.
1.

Universitá di Torino. ORCID: http://orcid.org/ 0000-0001-6097-1907 Contato: roberto.tessari.yj7f@alice.it 2. Universidade Federal de Alagoas. ORCID: http://orcid.org/ 0000-0003-0442-6837 Contato:

ivanildopiccoli@hotmail.com

Submetido em: 30/11/2016 Aceito em: 10/01/2017 


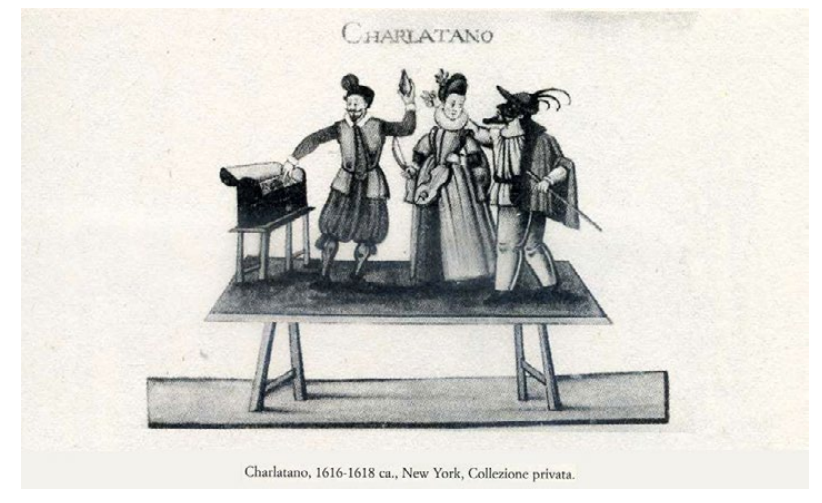

Charlatão em gravura de 1616-1618, coleção privada de Nova Iorque.

Delineando a história da medicina fraudulenta entre a Idade Média e o Renascimento, Piero Camporesi observa que "O século XV foi uma época de ouro para os cerretani, e assim também foi uma grande parte do século XVI; mas [...] as estações felizes não duram para sempre". Uma complexa rede de fatores alterou profundamente a sociedade italiana do pós Concílio de Trento:

A nova e mais rigorosa organização eclesiástica, saída do Concílio de Trento, a reorganização da assistência pública e até mesmo instituições de caridade por cidades e comunidades laicas, [...] o crescimento demográfico, a diminuição dos salários reais e o aumento correspondente do custo de vida, uma consequência da revolução nos preços, colocaram na cena europeia novas ondas de pobres [...]. Os novos, [...] muitas vezes provenientes da classe média, da pequena burguesia e artesãos, empurrados e impulsionados para as ruas tornando-se vagabundos da fome e da miséria, [...] sufocados e postos em crise pela mendicância que poderíamos definir de 'clássica'. (CAMPORESI, 1973, p. XCII-XCVI).

Com a mudança sociocultural, faz-se um contraponto a uma mutação terminológica, que, antes, tendia a confundir o mendigo-simulador (cerretani) com aqueles que oferecem duvidosos remédios para todos os tipos de males (ciurmatore, ciarlatano); após, vê-se o progressivo firmar-se da palavra ciarlatano - dos quais cerretano será destinado a se tornar sinônimo com função subalterna - para definir qualquer um que propõe ao mais vasto público, seja nas ruas ou nas praças, atrações espetaculares e medicamentos de duvidosa legalidade:

Parece provável que, no século $\mathrm{XV}$, se distinguisse entre cerretano (simulador) e ciurmatore (ciarlatano); [...] Em, Speculum [1485 d.C.] foi sempre utilizada a terminologia cerretanus, exceto no capítulo V [...] que aparece [...] ciarlatanus, no sentido de sinônimo da frequente palavra [...]. É razoável, portanto, inferir que os dois termos que começassem a ser uniformizados e a fundir-se no mesmo significado: o processo tinha de ser muito rápido, se algumas décadas após eles aparecem invertido no seu signifi- 
cado. Na verdade Maquiavel adota cerretano no significado de ciarlatano (charlatão medicastro) [...]. Enquanto que a mudança das condições históricas e sociais está morrendo na consciência dos falantes ao antigo significado ligados à esta mendicância "improvável", o termo antigo de 'ceretano' se torna comumente usado para indicar a sua função mais recente e torna-se de efetivamente um sinônimo alternativo (mas de igual valor) da palavra 'ciarlatano'3 (CAMPORESI, 1973, p. CXIV-CXV).

Este conjunto de fenômenos se desenvolve na península italiana ao longo de um arco cronológico que vai desde o início do século XVI, com o período imediatamente após o Concílio de Trento. Cerca de vinte anos após a conclusão do último, Tommaso Garzoni, no livro "Praça Universal de todas as profissões no mundo" (de 1585), homologa sem nenhuma reserva "ceretani" e "ciumatori" (impostores), mas - ao mesmo tempo - ele oferece uma definição surpreendentemente nova. Já não se trata mais de pessoas especialistas em várias formas de esmolas religiosas e medicamentos fraudulentos, mas de "formadores de espetáculos":

[...] quem quer contar em detalhes todas as formas e todas as maneiras que adotam o ceretani para fazer sua "venda", acaba por fazer coisas diversas. Só para falar de algumas, que por um lado da praça você vê o nosso galante Fortunato com Fritata [...] entretendo a brigada todas as noites [...]; fingindo novelas, encontrando histórias; formando diálogos; [...] cantar ao improviso; franzindo a testa em conjunto; fazendo a paz; morrer de rir; alternando varias formas; [...] e, finalmente, colocando para fora os seus recipientes para serem vendidos, desejando serem convencidos com as suas falas mais gentis. [...] entre tantas esboça uma historia popular risível no correto Toscano, e durante a qual a sobe uma prostituta no tablado/banco, relinchando como um fantoche de um jumento o seu Graziano: a roda de pessoas se une em torno dele, as pessoas ficam fixas para o ver e ouvir, [...] e neste momento a prostituta prepara um círculo sobre o banco e lança-se de quatro para pegar um anel fora do círculo, em seguida, jogando o corpo para traz pega uma moeda de duas espadas cruzadas, ela fica esparramada, despertando um estranho desejo das pessoas com sua lascívia gratuita. [...]. Não faltava Zan da Vigna de fazer ele agora à frente [...], onde as pessoas gargalham, vendo os gestos de macacos, e de outros babuínos [...]. Entre tantos outros o Mastro Paolo de Arezzo aparece na praça com um grande estandarte, longo e esticado, onde você vê um São Paulo, por um lado com a espada na mão, e do outro um amontoado de cobras que, assoviando, mordendo quase, como uma pintura, todo aquele que a olha (GARZONI, 1991, pp. 15-18).

O amplíssimo e detalhadíssimo afresco de uma ideal praça do século XVI descrito por Garzoni ilustra um mundo
3. Idem, p. CXIV-CXV. 
de "cerretani-ciumadori", onde quase não há mais espaço aos imitadores agora anacrônicos do 'boccagiano' Frei Cipolla. Os novos protagonistas dos lugares de mercado são movidos por um objetivo comum: "fazer seu comércio", conseguindo vender em grandes quantidades de recipientes em frascos ("bussoli") os medicamentos milagrosos (como os da Terra de Malta, um antídoto para o veneno de víboras, traficadas por "saopaulistas"). Mas o que, sobretudo, impressiona o observador é a matriz fantasmagórica de números e atrações encenadas com a finalidade autodivulgadoras por estes singulares "formadores de espetáculos": contadores de fábulas, improvisadores de canto e música, performances de contadores de histórias, monólogos e diálogos cômicos, provas de virtuosismos acrobáticos, pequenas cenas teatrais, jogos de ilusionismos e prestidigitação, exibições femininas habilmente misturadas com movimentos de contorcionismo e movimentos e posturas projetadas para aguçar o "lascivo" dos espectadores, movimentos processionais e paradas completas com bandeiras embelezadas por imagens de impressionantes efeitos especiais.

Tudo fabricado e colorido em cores brilhantes de um interminável festival de tipos fixos e de máscaras populares reconhecidas: o "belo" Fortunato, Zan Frittata, Fantoches e Bonecos, o doutor Graziano, várias mulheres denominadas soubrettes, Zan della Vigna etc. O olhar da testemunha permanece quase indiferente à inclinação da eliminação "terapêutica" (tão óbvio, segundo Garzoni, principalmente pelo capcioso e fraudulento), que deve ter finalidade exclusiva de todas essas atividades. Resultando, ao invés disso, por ser quase hipnotizado pela fascinante caleidoscópio de encontrar performatividades colocadas na obra de semelhantes indivíduos que, por um lado possuíam fingir virtudes médicas duvidosas ou inexistentes, por outro lado, são considerados por todos os efeitos autênticos e válidos de "fazedores de espetáculos".

É muito significativo, a este propósito, que o autor da Praça, querendo criar uma verdadeira e própria enciclopédia universal das profissões contemporâneas, acaba dividindo os novos especialistas do espetáculo unindo-os em três vozes e itens distintos de suas obras: os dramaturgos antigos e modernos, juntamente com profissionais atores-autores profissionais (como Adriano Valerini e Isabella Andreini), na categoria pseudoclássica dos "histriões"; todos aqueles que fazem jogos de ilusão e de prestidigitação estão no círculo infame de "mágicos/magos" e "feiticeiros"; uma massa confusa de autodenominados de curadores, que oferecem todos os tipos de performances em espaços abertos nos dias de mer- 
cado, dentro de uma classe específica de "fazedores de espetáculos" (a ser entendida como reais herdeiros do "cerretanismo" transportados para a "ciarlanteria"/charlatanismo).

A óbvia precariedade da catalogação adotada pela Garzoni constituiu uma primeira resposta provisória a uma dupla mudança cultural e antropológica da época. Por um lado, por configurar-se de uma sensibilidade difusa entre os quais vão dissolvendo os impulsos que levaram as massas a praticar quase por reflexo condicionado uma piedade cristã na qual o âmbito da mendicância era considerado sagrado, e qualquer forma de esmolas religiosas - mesmo fraudulentas - poderia ser bem sucedida, se ela fosse praticada em sintonia com as crenças supersticiosas vivas sem reservas. Por outro lado, a progressiva ameaçadora, a partir de meados do século XVI, de um verdadeiro e próprio mercado moderno do espetáculo: concebido e estruturado para propiciar e explorar as expectativas do divertimento de um público não mais elitista, mas potencialmente tendendo a incorporar também a infinidade dos estratos sociais. Os sinais eloquentes deste último fenômeno consistem na formação da primeira "fraternal companhia" de atores profissionais (Pádua em 1545), e dos primeiros testemunhos (aqueles contidos no Rime burlesque de Anton Francesco Grazzini, um pouco mais tarde no meio do século); as especificações são oferecidas aos espectadores pagantes fundadas sobre a presença de máscaras e o uso das técnicas de improvisação mímico-verbais. Em uma única fonte: a partir do conjunto de fatores que a história homogeneizará sob a cartilha de Commedia dell'Arte.

Essas duas mudanças - que são realizadas no fundo por um cenário desenhado e condicionado pelo contraponto entre o amanhecer da Reforma Protestante (1517), e ao meio- dia da Contra-Reforma Católica (1563) - contêm ambas em seu interior um fenômeno que de alguma forma está relacionado à dimensão religiosa da cultura: que os propõe um fim cômico - espetáculos de máscaras, o que parece constituir um enigmático "retorno do reprimido" no panorama italiano do período. Enquanto novos atores-autores das Fraternais Companhias de misterie (profissionais) estão inventando uma "comédia de zanni" que exclui o verossímil das personagens renascentistas (e substitui-lo com a verve surreal de uma máscara demoníaca reconhecida ao imaginário não-cristão da Idade Média), os novos cerretaniciarlatani, charlatães da praça, assumem o papel de terapeutas populares que utilizam do zanni, Pantalones, Dottores, Capitães etc. para estabelecer - por figuras impregnadas de auras demoníacos - um diálogo tentador e brincalhão com seu público. 


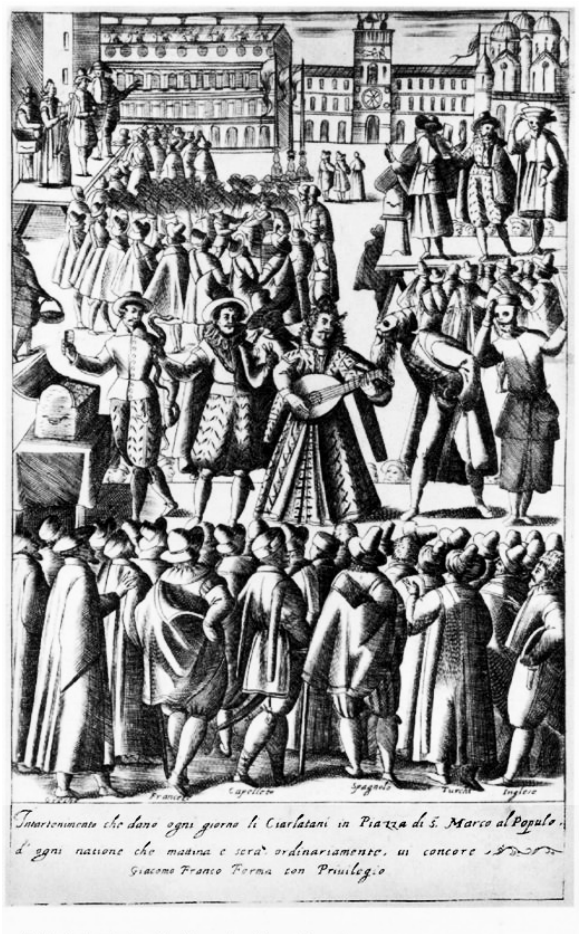

8. Istrioni e ciarlatani in Piazza San Marco, Venczia
Histriões e ciarlatani na praça de São Marco, em Veneza.

No primeiro caso, as orientações e os objetivos da operação devem ser todos marcados por nítidas intenções meramente (não que a fizeram ser laica) estéticas de divertimento. No segundo - como demonstradas exemplarmente, entre outras, as técnicas performativas dos "serpentari" (homem das cobras), de São Paulo - é evidente que os espectadores "ciarlataneschi" são colocados com malícia no cume que separa e une-se à confusão do desinteressado uso cômico-artístico da máscara, e uma hábil exploração da aura sagrada também em torno dela: de seus antigos valores de molde xamânico.

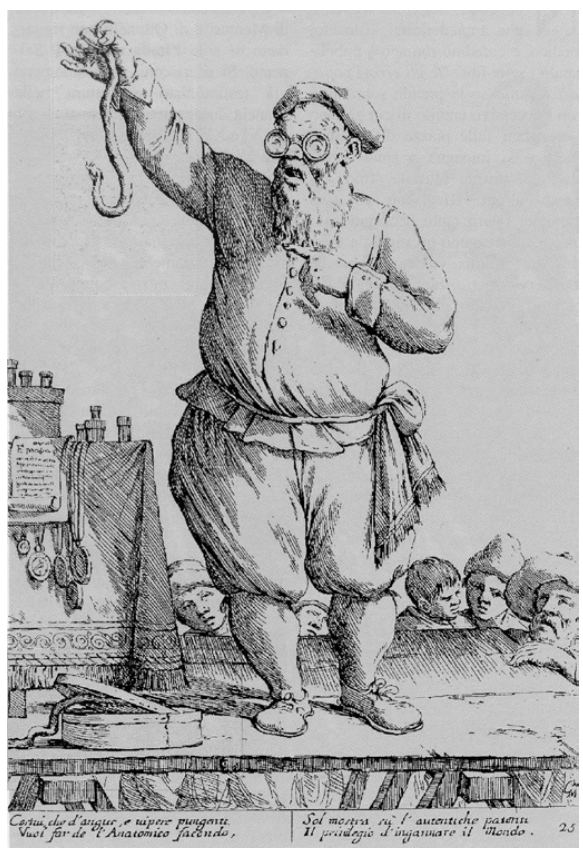

Ciarlatano sãopaulista com cobras. 
Esta complexa rede de fenômenos é à base das dificuldades com que se confronta Tommaso Garzoni quando ele deseja traçar um panorama exaustivo de todos aqueles que "fazem profissões" das artes do espetáculo em 1585, e que coloca no ponto focal brilhante do mundo em transformação dos "cerretaniciurmadori". Sessenta e cinco anos depois, pelo contrário, o jesuíta Domenico Ottonelli, ocupando-se da idêntica matéria, pode desenhar um catálogo tão claro como simples (embora bastante surpreendente, pelos critérios que orientam a sua lógica classificatória):

[...] faço uma distinção entre todos os recitantes de duas ordens: uma daqueles que são chamados comumente os comediantes, e estes fazem suas ações dentro das casas, nos cômodos ou salas ou lugares atribuídos. A outra forma é daqueles que se autonomeiam ciarlatani/charlatães, estes fazem seus entretenimentos e jogos/ apresentações em vias públicas, ruas ou praças de passagem; [...] recitadores/narradores [...] é nomeado participante também dos "senhores da Academia", e outros, que às vezes representam no teatro algumas diletantes ações; [...] Os ciarlatani tornam-se comediantes e se servem da comédia como meio eficaz para atrair ao banco/tablado, onde fazem o espaço de suas mercadorias e bussolotti. (OTTONELLI, 1652, p. 2).

Para Ottonelli, portanto, deve ser óbvio para qualquer um que existem três especificações para fazer teatro: aquela (de origem renascentista, e agora considerada subordinada) dos diletantes (amadores) praticados principalmente nas academias e nos círculos aristocráticos; aquelas que dão à vida os atores profissionais reunidos em companhias ativas nos espaços fechados habitualmente utilizados para uso teatral; aquelas de ciarlatani que realizam "seus entretenimentos e jogos/representações" nas praças, servindo-se "das comédias como meio eficaz para atrair ao banco/tablado". Uma vez que considera os seus espetáculos de diletantes como mero sub-fenômeno acessório, o jesuíta atribuiu igual dignidade e igual importância aos "commediantes" e os "ciarlatani". Preocupa-se, então, em especificar que a primeira marca distintiva de teatralidade "ciarlatanesca/charlatanistica" é dada pela proliferação - nele - de um infinito número de "jogos/representações maravilhosas concebidas ou utilizadas "para atrair". Destes fazem parte, antes de qualquer coisa, o mais ou menos amplo número de esquetes exibidos por ciarlatani com máscaras solitárias ou em duplas, cujo efeito cômico - segundo Ottonelli - deve ser catalogado dentro de quatro ideais itens: "1- [...] ridícula satírico; 2- Faceto; 3- Bufonesco e 4- Obsceno" (OTTONELLI, 1652, p. 442) Mas, então, constitui um componente principal da quase infinita proliferação dos números de atrações assim exemplificados: 
[...] o caminhar ou dançar sobre uma corda; o demonstrar força de Hércules; o uso de saltos mortais; a voar de um lugar para outro com uma corda; o jogar de armas de várias formas; o caminhar com as mãos e pés para cima; o fazer dançar e pular um animal, ou ainda, uma mulher vestida de homem; o enganar os olhos dos outros com várias destrezas com as mãos; o levantar um peso grandíssimo apenas com o a força do cabelo; o ferir alguma parte do corpo, e depois curar-se (OTTONELLI, 1652, p. 440).

Dentro de uma similar nebulosa de pequenas performances, assumindo um papel absolutamente importante com verdades e próprias representações complexas alimentadas da sofisticada linguagens especializadas da cena: o teatro de sombras, fantoches, bonecos, encenações onde há a ação - com acompanhamento musical - pequenos autômatos, outro "um meio braço" que se movimenta "por causa de [...] escondidos contrapesos", movendo-se no palco que os hospeda longos "algumas madeiras com entalhos sob a forma de canais, e que servem como ruas" (OTTONELLI, 1652, p. 466). Mas, principalmente, parece ser presença tanto comum como óbvia à prática de realizações de verdadeiras e próprias comédias de máscaras fundamentadas na improvisação, das quais Ottonelli se esforça para especificar em uma grande página seja a peculiar relação de funcionalidade a comercialização de "miraculosos" medicamentos propostos pelos ciarlatani, ou seja, todos os fatores que são úteis para mostrar como os espetáculos das praças devem ser considerados verificáveis quase sem reservas àqueles criados pelos ilustres cômico dell'Arte em suas "salas":

[...] fechem as caixas e levantem os pilares, o banco/tablado se transforma em lugar para a cena, cada ciarlatani em comediante, e dá inicio a um dramática recitação onde o uso do cômico vai entreter pelo espaço de cerca de duas horas o público com festa, com risada e gargalhadas (OTTONELLI, 1652, p. 456).

O testemunho de Ottonelli certifica, de um lado, a cada possível dúvida que - na metade do século XVII - um componente fundamental, talvez o mais popular e difundido, da nova civilização do espetáculo que já era estável em grande parte da Itália (e não privado de manifestações semelhantes em outros países europeus) é nutrido de um conjunto de performances e de representações oferecidos aos espectadores nas praças públicas, promovido e gerido (por vezes a sua própria, às vezes com a intrusão dos atores mais ou menos contratados) a partir do composto e infame microcosmo da ciarlataneria/charlatanismo.

No auge do período indicado, além disso, esta teatralidade difundida - e, pela opinião dominante, dignos sozinho ou em um altivo silêncio ou convicções depreciativos - tem, 
pelo menos em nossa península itálica ou em solo francês, os seus primeiros autores capazes de transmitir significativos testemunhos impressos do seu ofício: um Giulio Cesare Croce (1550-1509), por exemplo; ou os ruins redatores daquela litérature para dramaturgia que, a partir da segunda década do século XVII, tem sua marca registrada, em Paris, por diálogos ciarlataneschi entre as máscaras de Tabarin e de Mondor. E se trata de um fenômeno não apenas de amplíssimo alcance, mas também destinado para durar até a metade do próximo século, culminando - no lado francês - com a complexa e rica história do Théâtres de la Foire (cujo âmbito é determinar-se a história de um verdadeiro e única empresariado do espetáculo alternativo daqueles "autorizados"), e produzindo - por um italiano, onde inexistem fenomenologias alternativas destes alto-relevo - manifestações ainda não insignificantes. Como, por que não citar apenas um exemplo, a singular experiência de ciarlatanesca/charlatanesca de Buonafede Vitali (autonomeado como Anônimo): considerado e reconhecido por Goldoni em 1733, mais que um médico respeitável, foi criador e utilizava máscaras em suas encenações, era apreciado pela sua especialidade de possuir uma teatralidade da qual o jovem aspirante dramaturgo atribui úteis diálogos, seja como aprendiz, seja como com a função de "poeta da companhia" (TESSARI, 2013, p. 38).

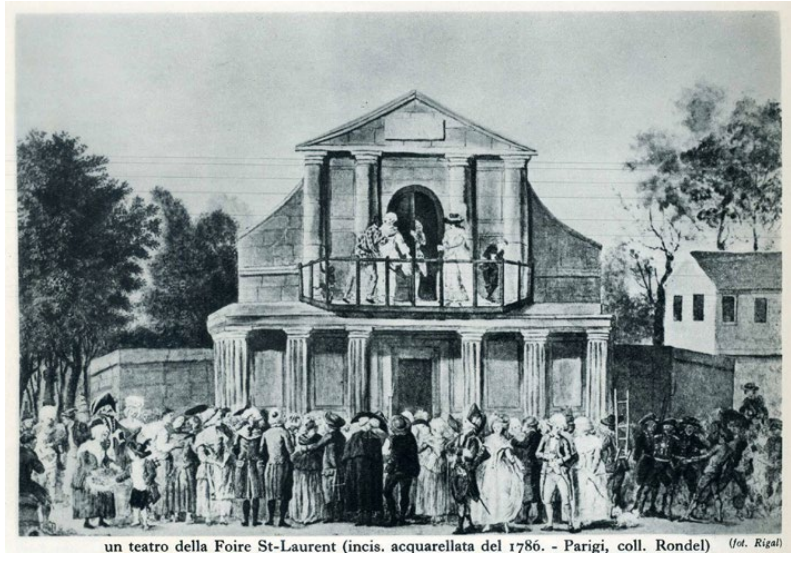

Théâtre de la Foire de Saint Laurente, aquarela de 1786, Paris.

Deste amplo campo da história do espetáculo, objeto de pesquisas aprofundadas, só no que diz respeito à origem e desenvolvimento do Théâtre de la Foire, não há ainda nenhum estudo adequado que possa retomar um panorama exegética geral satisfatória (ainda que exaustivo). Como não existe uma proposta interpretativa capaz de pode iluminar os significados e funções - principalmente no que concerne à sugestiva e enigmática relação entre o equívoco e mal-entendido dito terapêutico das múltiplas atividades ciarlatanesche -, na dúvida utilizo de performances e comédia como indispensáveis ferramentas unidas 
reivindicadas ao divertidamente "calmante", e aquele imaginário folclórico-religião que se refere tanto às máscaras quanto aos muitos rituais tardios - "pseudo-xamânicos" - típicos dos cerimoniais ciarlatanescos.

A mesma origem de certas práticas concernente aos médicos montambanchi (que fazem sobre um tablado) pós-renascentistas permanecem envoltos nos mistérios, e acima de tudo permanecem obscuros eixos importantes no processo que os levou a se fundir inseparavelmente ao exercício da medicina entre as classes mais baixas e com uma movimentada e nebulosa nuvem de atrações espetaculares seja - acima de tudo - com práticas cênicas de amplas semelhanças com aquelas da Commedia dell'Arte. Se for esclarecida em formas satisfatórias a fenomenologia das mutações terminológicas de cerretano levado até ciarlatano, permanece a vaga amplitude cronológica entre as quais deveriam verificar aos concretos eventos históricos ocorridos que teriam mudado: um período de tempo que se abre do fim do século $\mathrm{XV}$, mas que continua a ser impossível determinar com precisão o seu exato culminar.

Com base nos limitados documentos restantes, podemos ter a certeza de que, em 1585, em relação aos ciarlatani-espetáculos constituíam um dado tão seguro quanto óbvio e agora difundido nas praças da Itália. Muito mais difícil é supor uma data plausível para o seu primeiro manifestar-se em formas tais de serem comparadas com as que serão patrimônio específico, após 1545, dos novos atores profissionais. A notícia mais correta parece indicar que a performance dos ciarlatani, diz respeito às últimas duas décadas do século XVI, se nos limitarmos as atrações descritas por Garzoni. Nenhuma comédia de máscaras, em suma, sobre os bancos/plataformas ao ar livre, antes de então.

Restam, no entanto, vacilar entre esta potencial certeza, determinados versos escrito por Anton Francesco Grazzini em torno da metade do século. Se a sua Rime Burlesche - em pelo menos dois casos - parece lamentar com raiva os favores concedidos pela juventude florentina por nominar (e também retratar como fraudulentos e "obscenas") as atividades dos cerretani e ciurmadori, e convidar o público habitual deste último para frequentar a mais nova commedia que tem por protagonista "atores mascarados de Zanni: '[...] certa é que recontar sua fadiga, / e este cerretano deixou passar / falso mentiroso e cheia de fraude e enganos" (GRAZZII, 1882, p. 48). Mas como seria possível, ao Lasca, propor um confronto paralelo entre comediante profissional e cerretano-ciarlatani, se este último não tivesse oferecido à sua própria audiência os espetáculos de alguma forma parecidos e comparáveis àqueles de uma Fraternal Companhia (e, talvez, centrado em torno das mesmas figuras mascaradas)? 


\section{REFERÊNCIAS}

CAMPORESI, Piero. Il libro dei vagabondi. Torino: Einaudi, 1973. GARZONI, Tommaso. De' fonnatori di spettacoli in genere, e de' cerretani o ciurmadori massime. In: MAROTTI, F., ROMEI, G. La professione del teatro. Roma: Bulzoni, 1991.

GRAZZINI, Anton F. Le rime burlesche, a cura di Verzone C. Firenze: Sansoni, 1882.

OTTONELLI, Domenico. Della christiana moderatione del theatro, t. III, Firenze: Bonardi, 1652.

TESSARI, Roberto. La Commedia dell'Arte. Genesi d'una società dello spettacolo. Bari-Roma: Laterza, 2013. 